CALEI-
DOSCOPIO

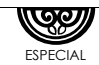

DE GÉNERO

\title{
Geografías ciudadanas y femeninas. Perspectivas desde tres identidades culturales
}

MARÍA REBECA PADILLA DE LA TORRE'

\section{RESUMEN}

En este texto se revisa el cruce entre la identidad cultural y de género entre los hallazgos de un estudio más amplio que tuvo como propósito analizar los sentidos que adquieren las prácticas mediáticas en la construcción de ciudadanía entre distintas identidades socioculturales en Aguascalientes, México. El discurso de mujeres japonesas, defeñas y aguascalentenses se analiza a partir de la etnografía y entrevistas para ilustrar las diferencias y desigualdades entre las ciudadanas de esta ciudad. El estudio muestra que se imponen la lógica y el sentido de pertenencia a una identidad cultural por encima de la de género o la de una ciudadanía capaz de construir consensos a través de la diferencia.

Palabras clave: ciudadanía cultural, género, identidades urbanas.

\section{ABSTRACT}

In this text the intersection between cultural and gender identity is inquired among the findings of larger study which purpose was to un-

1 Profesora investigadora del Departamento de Comunicación de la Universidad Autónoma de Aguascalientes. rebecapadilla.uaa@gmail.com,mpadilla@correo.uaa.mx. 
derstand the meanings media practices acquire in the construction of citizenship between different socialcultural identities in Aguascalientes, México. The discourse of women from Japan, México City and Aguascalientes are analyzed through ethnography and interviews to illustrate the differences and inequalities between women citizens of this city. The study shows that the logic and belonging to a cultural identity are imposed above gender identity and a citizenship capable of building consensus across difference.

Key words: cultural citizenship, gender, urban identities.

El concepto de ciudadanía política es muy claro, se define a partir de la legislación de un Estado-Nación que determina las condiciones necesarias para otorgar el estatus de pertenencia y, derivado de ello, los derechos y obligaciones que se adquieren ante una comunidad política determinada. En la práctica, ha constituido un reto para los estados garantizar el mismo reconocimiento y ejercicio de sus derechos a todos aquellos que acepta como ciudadanos. Incluso, el problema ha sido más grave porque a lo largo de la historia, y aún en la actualidad, se les ha negado la ciudadanía a personas que participan en la comunidad. No han sido considerados miembros legítimos de ella con base en el argumento de que las características y rasgos de su identidad, sea cultural, de género, religioso, u otro, no tienen la necesaria valía para pertenecer. El caso de las mujeres y los migrantes han sido emblemáticos. Esta problemática se resolvería en primera instancia en el marco legal y en las prácticas de un Estado-Nación, sin embargo, es muy importante además la iniciativa y el papel que los propios ciudadanos tienen en el reconocimiento de los otros en su vida cotidiana, lo cual tiene la capacidad de replantear el sentido de pertenencia de "abajo hacia arriba".

Por ello, este artículo se enmarca en la noción de ciudadanía cultural, la cual, de acuerdo con Renato Rosaldo (1999), no parte de la relación estado-ciudadano, sino de la perspectiva de los propios ciudadanos, de ciudadano-ciudadano, con énfasis en la identidad cultural. En este texto se revisan las perspectivas de mujeres de distintas identidades socioculturales ${ }^{2}$ para indagar cómo asumen su pertenencia, no respecto a un Estado-Nación, sino con relación a otros ciuda-

2 En sentido estricto, se emplea el término sociocultural y no cultural, porque no se abordan sólo culturas totalmente distintas con base en diferentes razas, sino que además se revisan diferencias basadas en el ámbito socioeconómico. 
danos y ciudadanas, en este caso entre los habitantes de la ciudad de Aguascalientes, México. El propósito de analizar estas perspectivas es explorar, de acuerdo con la propuesta de Rosaldo, cómo la diversidad actúa en las posibilidades de construcción de consensos entre los residentes. Se indaga si estas mujeres trascienden la perspectiva de su propia identidad sociocultural para construir ciudadanía entre las mujeres de su misma ciudad.

Este texto inicia con una discusión que cuestiona el concepto tradicional de ciudadanía y lo confronta con los sentidos ciudadanos que se viven desde las identidades culturales, que conforman alteridades que implican no sólo diferencias, sino desigualdades, lo que impide la construcción de una ciudadanía en común. En un segundo apartado se describe el contexto y el marco metodológico del estudio para, posteriormente, compartir la perspectiva de las mujeres en estas identidades socioculturales.

\section{CIUDADANÍA CULTURAL Y TEORÍA FEMINISTA}

El concepto de ciudadanía, en sentido estricto, se define con relación a la comunidad política de un Estado-Nación y no con relación a la ciudad, que es en donde se inscribe este trabajo. Sin embargo, las raíces históricas y etimológicas del término significan "el natural o vecino de una ciudad". Las dimensiones clásicas de la ciudadanía son la civil, política y social (Marshall, 2005), y se consideran aún como emergentes la económica y la cultural. Por otra parte, la ciudadanía se compone por elementos esenciales que son el "estatus" o el reconocimiento legal de derechos y obligaciones, que pueden legítimamente reclamarse para la plena realización del hombre o la mujer; una identidad que se refiere al sentir y actuar específicos que comparten los miembros de una misma comunidad política; unas prácticas o participación en la definición de la vida pública, orientadas por valores compartidos; y un proceso institucional a través del cual se instituyen, se respaldan y regulan los derechos y deberes mediante la ley (Ramírez, 2003; Sermeño, 2004).

Knight y Harnish (2006) señalan que prevalecen dos sentidos en los diversos discursos y significados implícitos en el pensamiento occidental sobre la ciudadanía. En primera instancia predominan los discursos con vetas en los paradigmas liberal y el cívico republicano. Un 
segundo grupo los describen como discursos críticos que cuestionan los dos anteriores, este grupo comprende la noción de "ciudadanía cultural" y los discursos sobre ciudadanía feminista, reconstruccionista, queer y transnacional. Tienen en común que plantean preguntas básicas sobre la identidad, sobre quiénes somos como ciudadanos, sobre quiénes pertenecen con base en el criterio de la territorialidad y sobre cómo promover la práctica ciudadana. Dichos autores señalan que estos discursos que llaman "críticos" se encuentran con mayor vitalidad en el campo de la discusión teórica y académica, y menos en la práctica y formación ciudadana. De manera más específica, los discursos sobre ciudadanía cultural cuestionan la manera en que grupos étnicos, minorías lingüísticas y otros grupos culturales han encontrado que la ciudadanía es un rol y una identidad que se adquiere a elevados costos, ya que las identidades ciudadanas implican en ocasiones una asimilación que resulta dañina y poco compatible con otras identidades de pertenencia de algunos individuos y grupos.

A Renato Rosaldo (1999) se le atribuye el origen de la noción de ciudadanía cultural y argumenta que el concepto de ciudadanía se plantea como universal sólo a nivel formal, porque en la práctica es excluyente. ${ }^{3}$ Históricamente puede constatarse que se reservó como un derecho sólo para algunos varones privilegiados y negado durante un periodo de tiempo amplio para las mujeres. La ciudadanía subraya la igualdad, y en este sentido la condición de su igualdad es su semejanza.

\footnotetext{
Son iguales porque son iguales de género, de idioma, de cultura, y ésa es la condición de su igualdad, todos son lo mismo, todos son semejantes. En este sentido, la cuestión de la ciudadanía a este nivel universal parece ser un asunto muy sencillo: o tienes documentos o no los tienes; o eres ciudadano o no lo eres (Rosaldo, 1999: 1).
}

Para este autor, la ciudadanía cultural se expresa en dos ejes, el primero es que la expansión de la ciudadanía implica no solamente la relación estado-ciudadano, sino la relación ciudadano-ciudadano, que se refiere al trabajo en grupos sociales, sin la intervención del

3 Existen otras perspectivas que abordan la relación entre ciudadanía y cultura como la que defiende los derechos culturales que se refiere a los garantes para disfrutar y producir en igualdad el patrimonio cultural (UNESCO, 2009). Por otra parte, existe la noción de ciudadanía cultural como el derecho, no sólo el reconocimiento y la pertenencia, sino a un ejercicio político distinto dentro de un Estado-Nación con base en la diferencia cultural (Kymlica, 1996). 
Estado en donde se busca un reconocimiento al sentido de pertenencia y una reivindicación de derechos en el sentido substancial y no formal. El segundo eje se refiere a que cuando se habla de ciudadanía cultural, es necesario conocer las aspiraciones legítimas de los grupos subordinados. Se cuestiona quiénes pertenecen al grupo que impone su punto de vista sobre los conceptos de "bien común", "espacio público" y "sociedad civil" (Rosaldo, 1999). La noción formal de ciudadanía no logra incorporar en el plano de lo real el problema de la diferencia y reconocer que son precisamente las desemejanzas lo que permite entender cómo se nutre, se entiende y practica desde el punto de vista de los ciudadanos, no privilegiados, que son la mayoría. En este mismo sentido, las feministas argumentan que ha prevalecido una perspectiva parcial que corresponde a ciudadanos predominantemente masculinos, blancos, heterosexuales, propietarios, sin discapacidades, excluyendo las experiencias y la vida femenina, entre otras (Moreno, 2005).

En este sentido, resulta valioso visibilizar la diversidad en este texto entre mujeres, que aun cuando evidentemente son unas cuantas comparadas con el número que puede encontrarse en esta ciudad, permiten enriquecer la perspectiva homogénea que prevalece en el concepto y los discursos sobre ciudadanía. Con el fin de comprender mejor los casos de mujeres que se presentarán más adelante, además del término de ciudadanía, se exponen brevemente las ideas centrales del pensamiento feminista. A pesar de la diversidad de enfoques que derivan de él, existen varios elementos en común. Fundamentalmente, pretende estudiar la vida social y la experiencia humana desde la perspectiva y experiencias de las mujeres, éstas son el centro del proceso de investigación, ya que constituyen una mirada del mundo distinta a la del hombre y a la vez potente, debido a la riqueza que implica la vida femenina. Asimismo, la teoría feminista trabaja en las lógicas de la academia, pero con el claro propósito de promover una mejor existencia para todas las mujeres, dadas las históricas desigualdades a las que han estado sujetas. En consecuencia, esta teoría está a favor de desnaturalizar todo poder que tenga como resultado la inequidad entre los seres humanos (Madoo y Niebrugge-Brantley, 1993).

El campo académico explica que del amplio aporte intelectual del pensamiento feminista ha resultado clave el concepto de género, que trasciende la categoría de lo femenino sujeto sólo a lo biológico y se enfoca a comprender el género "como un mecanismo que estructura 
los mundos materiales y simbólicos y nuestras experiencias en ellos" (Van Zoonen, 1994:3), el cual constituye una perspectiva que no es asumida por otros pensamientos sociales. Además del género, como una construcción social y en el lenguaje, el segundo concepto central en el pensamiento feminista es el poder. El poder se construye desde el discurso y naturaliza las relaciones de subordinación a las cuales se encuentran sometidos diversos actores sociales, con base no sólo en la construcción social de lo femenino, sino a partir de diversas identidades como la etnia, la edad, el nivel socioeconómico o la religión, entre otras, a las cuales se les atribuyen injustamente ciertas características esenciales con base en las cuales se argumenta la legitimidad de las relaciones desiguales y subordinadas entre diferentes identidades. Esta lógica niega la construcción social y arbitraria de muchos atributos que se les otorgan o niegan a las identidades, como en el caso de la mujer, y tampoco reconoce lo variable que éstos son a través de la historia o entre distintas culturas.

\section{ANTECEDENTES Y LA METODOLOGÍA DEL ESTUDIO}

Este trabajo se llevó a cabo en la ciudad de Aguascalientes, México, que sin duda comparte similitudes con otras ciudades. A principios de 1980, el Gobierno del Estado emprendió un ambicioso proyecto de industrialización, basado en la inversión extranjera, que encontró respuesta en la empresa automotriz con inversión japonesa. Durante esta década se inició un acelerado crecimiento urbano y poblacional, se transformó su economía primaria hacia la manufactura y los servicios, convirtiendo la ciudad en un polo de atracción para la inmigración debido a la creación de empleos. Además, se empezaron a gestar los cambios sociales y políticos que dieron lugar al fin del gobierno del Partido Revolucionario Institucional (PRI) que duró setenta años en todo México y la posibilidad de una alternancia de partidos en el gobierno. Estas dinámicas transformaron la ciudad. Uno de los cambios más evidentes fue la intensificación de la diversidad cultural. Hasta entonces, la inmigración había sido escasa y en su mayoría de zonas cercanas con rasgos que no representaban diferencias culturales radicales.

La creciente diversidad sociocultural en la ciudad de Aguascalientes detonó la realización de una investigación que planteó compren- 
der, desde la perspectiva de la diversidad ciudadana, el sentido de ser habitante de esta ciudad inserta en acelerados cambios (Padilla, 2012). ${ }^{4}$ El presente trabajo da a conocer resultados parciales del estudio más amplio, centrándose fundamentalmente en los segmentos de las entrevistas en donde las mujeres relatan su situación como mujeres en esta ciudad desde la identidad sociocultural a la que pertenecen. En esta investigación, los sujetos de estudio no se eligieron a partir de una muestra estadística clásica, distribuida entre género, edad, profesión o estrato socioeconómico, el interés se centró en privilegiar la diferencia sociocultural que se vive en la ciudad entre identidades urbanas.

Con el apoyo de estadísticas, se trabajó un juego de la diferencia (Holstein y Gubrium, 1998) que partía de las características de los nativos para identificar cuáles serían las comunidades urbanas que representan un claro contraste. En primer lugar, fue evidente que los extranjeros en la ciudad serían una primera alteridad, por esa razón se eligió la comunidad de japoneses que habitan en la ciudad a partir de principios de la década de 1980 debido a la instalación de las plantas automotrices con inversión japonesa. Posteriormente, se identificó que el grupo de inmigrantes nacionales más numeroso era el de la Ciudad de México. El sismo de 1985 intensificó los propósitos que ya existían para descentralizar las instituciones y algunas funciones del Gobierno Federal, las cuales históricamente han tenido su sede en la Ciudad de México. El Instituto de Estadística y Geografía (INEGI) eligió a Aguascalientes como su nueva sede de operaciones y entre 1986 y 1987 desplazó aproximadamente a tres mil de sus empleados con sus familias. Para la entonces pequeña ciudad, esta inmigración fue un

$4 \quad$ En esta investigación se analizaron las diferencias culturales que existen en una ciudad y el papel clave que tienen los referentes mediáticos, tanto los tradicionales medios masivos de comunicación como las tecnologías de información y comunicación, es decir, cómo se asumen como ciudadanos. Los casos que se examinaron fueron los japoneses, originarios de la Ciudad de México, aguascalentenses y la Iglesia de Jesucristo de los Santos de los Últimos Días; esta última no se incluye en este trabajo. El estudio más amplio se basó en una intensa etnografía y entrevistas a miembros de estas comunidades. Los hallazgos mostraron que entre las diferentes identidades culturales se dan prácticas mediáticas orientadas por lógicas muy distintas que conforman diversas geografías mediáticas y ciudadanas que impiden una participación en términos equitativos en la conformación de una ciudadanía en común. Por esta razón, en el título de este texto se mantiene la noción de geografías, en un sentido metafórico para describir la diversidad de la ciudadanía y a la vez, el matiz que adquiere desde la perspectiva de estas mujeres. 
acontecimiento que quedó marcado en su memoria colectiva como una de las inmigraciones con mayor impacto. El estudio se completó con los casos de dos comunidades aguascalentenses nativas, una de elite, los socios del Club Social y Deportivo El Campestre; y otra comunidad de colonos de una de las colonias marginales y populares de la ciudad, la Vicente Guerrero.

En la investigación más amplia, estos casos fueron abordados a través de etnografía y entrevistas a los miembros de estas comunidades, en cada una se eligieron diez informantes que se entrevistaron a profundidad; de este cuerpo de informantes, la mitad fueron mujeres. ${ }^{5}$ Cada entrevista fue examinada a partir del análisis crítico del discurso con el objetivo de reconocer cómo se definían y asumían como una identidad sociocultural en la ciudad (Fairclough, 2003; Jäger, 2003).

En los siguientes apartados, se abordan tres casos de identidades socioculturales. Primeramente, se da a conocer el contexto y principales rasgos de las comunidades de japoneses, inmigrantes de la Ciudad de México, y dos distintos estratos socioculturales de aguascalentenses. Posteriormente, se afina la mirada entre los hallazgos más amplios del estudio para centrarnos en lo que dan a conocer las mujeres sobre su situación con base en su identidad sociocultural como ciudadanas o mujeres en la ciudad.

\section{IDENTIDADES CULTURALES Y FEMENINAS}

\section{La comunidad japonesa en Aguascalientes}

En el caso de los japoneses, se describirán en primera instancia algunos de los rasgos fundamentales que viven en común sus hombres y mujeres; ambos se encuentran envueltos en varias paradojas. A partir de la posguerra, los japoneses han sido desplazados a distintos lugares en donde existe inversión y producción japonesa, generalmente se envían por periodos de tiempo de tres a cinco años; luego vuel-

5 En el estudio del cual deriva esta investigación (Padilla, 2012), se llevó a cabo trabajo de campo entre estas comunidades de enero de 2007 a septiembre de 2008, y se realizaron 65 entrevistas en total, de las cuales 40 se examinaron mediante el Análisis Crítico del Discurso (ACD). Para este trabajo se revisó el diario de campo y las 40 entrevistas realizadas para identificar los segmentos que se referían propiamente a las mujeres. 
ven a Japón y quizás sean nuevamente desplazados. A principios de 1980, cuando recién llegaron a la ciudad, era difícil su vida debido a las profundas diferencias culturales. Estas dificultades los motivaban a buscar la ayuda de los locales a pesar de que su cultura -a diferencia de la latinoamericana-, privilegia relaciones sociales distantes, sobre todo con extranjeros. Paulatinamente, los japoneses ahora se desenvuelven cada vez menos integrados a la vida sociocultural de la ciudad. La globalización ha introducido varios negocios y servicios que se encuentran en la mayoría de las ciudades del mundo, lo que permite a esta población empresarial mantener su estilo de vida independientemente de la ciudad en la cual vivan. Es una situación de vida que suscita varias preguntas, ¿por qué se crea un estilo de inmigración distinta que no se da en términos de desigualdad y prejuicio, sino que se da en condiciones de privilegio? Se trata de una comunidad con altos ingresos y acceso a la tecnología de información y comunicación; esto les permite mantenerse cercanos a su país y al estilo de vida japonés contemporáneo y, paradójicamente, la ciudad en donde viven es lo más ajeno y extraño para ellos. A pesar de que los japoneses tienen una presencia de casi treinta años en la ciudad, permanecen como una población "invisible", debido a su conciencia de ser extranjeros, a los prejuicios y miedos frente a un México diferente e inseguro, y a su condición de habitantes temporales en la ciudad. Habitan la ciudad en una situación de autoexclusión, no económica sino sociocultural que ellos mismos han definido metafóricamente como vivir en la ciudad "en tercera persona".

\section{Las mujeres japonesas}

En el estudio de esta comunidad se distinguieron las siguientes situaciones desde la mirada de sus mujeres. La familia, la vida cotidiana y los roles de género se ajustan y cobran sentido en la lógica empresarial. En los diálogos con las mujeres japonesas provocó extrañeza la manera en la que asumían con absoluta naturalidad que una mujer japonesa, con una alta escolaridad y experiencia laboral, usualmente dejara su propia carrera al casarse y de manera inevitable al nacer sus hijos. Ellas explicaron que no lo entienden como una imposición patriarcal e injusta por parte de sus parejas, sino como una lógica que es indispensable seguir por el bien de la familia, la empresa y la nación. Las condiciones y exigencias del trabajo en una empresa vuel- 
ven prácticamente imposible que ambos padres trabajen y consideran que las mujeres están en mejores condiciones de cuidar a los hijos y supervisar su educación para que, a su vez, se encuentren formados adecuadamente para integrarse con éxito al exigente mercado laboral japonés.

Hay muchas esposas que su esposo trabaja en una empresa, pero la esposa no puede trabajar, porque su esposo está recibiendo dinero y no puede trabajar su esposa. Por eso su esposa puede ser voluntario o hacer artesanía, no sé (sic). ${ }^{6}$

Otra responsabilidad que tienen las mujeres es la de administrar los recursos económicos y patrimoniales de la familia. Los hombres se centran, en general, exclusivamente en sus tareas profesionales. Las mujeres ven en ello una oportunidad de desarrollo, más que una desigualdad. Ellas tienen una capacidad adquisitiva que les permite procurar seguir cultivándose y desarrollar varias actividades como la música, artes plásticas y deportes, además de supervisar la educación extracurricular de sus hijos. Sin embargo, algunos estudios (Ortiz, 2003) y los mismos japoneses comentaron que en Japón esta forma de vida está siendo cuestionada principalmente por los jóvenes.

En Aguascalientes, las empresas automotrices han generado una escuela sólo para hijos de japoneses; en ella, las madres de familia se relacionan y han conformado la Asociación Jacarandas. Ésta apoya a la escuela en sus tareas, pero principalmente constituye una red de soporte entre las familias japonesas.

Como las mamás japonesas siempre están en casa y pueden participar en cualquier cosa o cualquier evento en la escuela japonesa, ¿verdad?, entonces, no aceptan otro tipo de persona, entonces, para enviar a sus hijos a la escuela japonesa tiene que tener esposa libre, que pueda atender 100\% las actividades de la escuela (sic). ${ }^{7}$

Las mujeres son quienes se enfrentan a las tareas de la vida cotidiana en un entorno totalmente ajeno y con otras costumbres. Organizan el hogar y los problemas diarios solas, debido a que sus esposos cumplen con un exigente trabajo. Las esposas ingresan al país como

Entrevista realizada a maestra japonesa, 30 años, el 27 de agosto de 2007

Entrevista realizada a traductora japonesa, 40 años, 5 de octubre de 2007. 
la esposa de un "visitante, no inmigrado", y por ello no tienen formalmente permiso para trabajar. Además, sería difícil en un país extranjero, en donde no dominan el idioma, se encuentran de manera temporal y con escaso apoyo de su esposo. Precisamente por estas condiciones, su familia requiere mayores atenciones de su parte, por lo que las mujeres japonesas nunca asumen actividades laborales en la ciudad a pesar de su alta escolaridad.

Las japonesas en Aguascalientes aprovechan la vida en el extranjero para aprender el idioma, algunas artesanías como herrería o telares en la Escuela de Artes y Oficios, y se organizan entre sí para conocer la cultura mexicana, por ejemplo su gastronomía. También se reúnen para realizar actividades culturales, tienen un coro y entonan canciones japonesas, cocinan entre sí y practican deportes, principalmente el golf. Algunas han tenido la inquietud de trabajar a manera de voluntariado en la ciudad, sin embargo, las que han estado en otros lugares, como la ciudad de Buenos Aires, explicaron que en Aguascalientes no hay una organización formal vinculada al Gobierno del Estado, $u$ otra instancia, que las involucre, y las japonesas que llegan con esta inquietud no encuentran dónde desarrollarla.

Debido a que su actividad no se centra totalmente en la empresa, las mujeres japonesas son las que establecen los pocos vínculos con otros habitantes de la ciudad. Reconocieron que sus vecinos son quienes las han ayudado en algunas ocasiones en problemas de la vida diaria; sin embargo, entre ellas mismas es donde encuentran el principal apoyo.

Señoras a veces tienen contacto con otras señoras que viven aquí, pero los hombres jamás (sic) ${ }^{8}$

Las mismas mujeres se organizan para mantener actualizado un directorio en japonés de los establecimientos en la ciudad, con sus domicilios y teléfonos, a donde pueden acudir para satisfacer sus diversas necesidades, como servicios médicos, compras, clases extracurriculares para los niños, entre otras. Ellas se ayudan para enseñarse a manejar en la ciudad, en la lógica del carril derecho, porque en Japón se maneja hacia la izquierda. Comentaron que en esta ciudad conducir ha sido sencillo, debido a que es "redonda" y está organizada con

8 Entrevista realizada a ama de casa japonesa, 42 años, el 20 de septiembre de 2007.

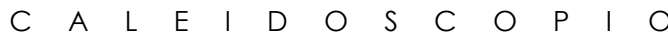


anillos periféricos, lo cual permite una orientación más fácil que en la complejidad de Tokio. En general, las mujeres japonesas aprenden de manera muy eficiente a desenvolverse en su hogar temporal.

Las de mayor edad explicaron que se está perdiendo entre las mujeres jóvenes el interés por asumir tareas de labor social entre la población, y por integrarse y aprender de la cultura local. Aclararon que en el pasado y en otras ciudades latinoamericanas, las mujeres japonesas han trabajado con algunas organizaciones o con el gobierno ofreciendo apoyo durante su estancia. Ahora las mujeres mantienen su estilo de vida lo más parecido posible al de Japón y se interesan en los nuevos países más con una actitud turística que social. ${ }^{9}$

Un actor importante con relación con la comunidad japonesa en Aguascalientes es el Gobierno del Estado, aunque su relación es de otra naturaleza, más ligada a los aspectos formales del ámbito económico y laboral, y en un ambiente masculino. Existen pocas mujeres japonesas en los niveles directivos de las empresas, la mayoría de ellas trabajan como traductoras. Además, en los tratos con los locales, los japoneses prefieren a los funcionarios varones.

\section{Inmigrantes de la Ciudad de México}

En este caso, tanto los hombres como las mujeres dieron cuenta de que en ocasiones los prejuicios y el conflicto entre la diferencia no siempre se da entre culturas totalmente distintas, sino entre connacionales. Para los nativos, los capitalinos son los culpables de los cambios en su ciudad. La creciente industrialización y urbanización han ocasionado varios problemas que no existían, como la creciente inseguridad, que se ha vuelto recientemente aún más grave debido a su vinculación con el narcotráfico. Desde la llegada de los primeros inmigrantes de la Ciudad de México, se organizó una campaña de rechazo con el lema: "haz patria, mata a un chilango", este último es el nombre despectivo con el cual se conoce a los originarios de la capital en México. Ellos explicaron que venían del contexto de la gran ciudad en donde se requieren habilidades para competir entre una población de veinte millones. Además, es necesario realizar todo con rapidez y se practica una cultura ciudadana distinta en donde se tiene una alta conciencia de exigir y ejercer sus derechos. Por el contrario, en la ciudad a la que

Entrevistas realizadas el 20 y 28 de septiembre, y 19 de octubre de 2007. 
llegaron, para los nativos no era necesario hacer las cosas con rapidez, el tiempo se comprende en otro sentido y la cultura ciudadana se basa en las relaciones de parentesco y amistad. Por ello, las actitudes de los capitalinos, en ocasiones fueron interpretadas como agresivas, competitivas y fuera de lugar. Durante la investigación se comprobó que persisten serios prejuicios hacia los inmigrantes de la gran ciudad, a pesar de que éstos tienen ya más de tres décadas de constante inmigración a Aguascalientes. Actualmente, esta comunidad está orgullosa de su "visibilidad" en la ciudad, al haber logrado integrarse y enriquecerla por ser una comunidad, en general, con mayor escolaridad, que activó la economía, aportó elementos culturales con arraigo prehispánico en tradiciones y gastronomía, y promovió una cultura ciudadana más participativa.

\section{Las mujeres capitalinas}

En el caso de las mujeres, específicamente las trabajadoras de menor nivel socioeconómico, de manera constante hicieron referencia al hecho de lo que significó ser "chilanga y mujer" en el contexto de Aguascalientes. En los inicios, su vida familiar fue muy difícil al llegar a un lugar que había que construirse tanto en el hogar como en el trabajo, el criar hijos al paralelo de la vida laboral y en un contexto de prejuicio hacia las mujeres que trabajaban. En el INEGI ${ }^{10}$ los hombres "hidros" fueron muy severos con ellas y en general, en la ciudad, se corrieron rumores que las trabajadoras "chilangas" del INEGI eran sexoservidoras. ${ }^{11}$ Percibían cómo los aguascalentenses, tanto hombres como mujeres, las criticaban no sólo por ser defeñas, sino además por salir del hogar y trabajar.

Otra diferencia que les pareció muy notoria fue que en Aguascalientes aún prevalecían modelos tradicionales de familia, entre las relaciones de pareja y en el papel de la mujer. Además, todos los aguascalentenses son muy religiosos, "muy mochos". Algunas costumbres de los "chilangos" fueron duramente criticadas, como su forma de vestir y desaliño los días de descanso o para asistir a misa; que algunos

10 Como ya se explicó, el estudio de la comunidad de inmigrantes de la Ciudad de México se centró en el INEGI, dado que constituía una comunidad con la cual trabajar con esta identidad sociocultural de manera más precisa.

11 En las entrevistas, se explicó que hubo algunos casos de secretarias que realizaban una doble profesión, pero el prejuicio se extendió hacia todas las trabajadoras del INEGI.

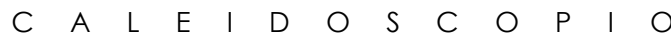


hombres hicieran tareas domésticas, que las mujeres trabajaran o se organizaran para salir a divertirse solas. Las mujeres originarias de la Ciudad de México consideran que la inmigración desde la capital ha sido significativa para lograr cambios culturales entre los aguascalentenses. Señalan que los modelos de familia y el papel de la mujer en Aguascalientes se han abierto al cambio y ahora se aceptan con mayor naturalidad divorcios, familias recompuestas, solteras que vivan solas, madres de familia que trabajen y padres de familia que realicen tareas domésticas.

\section{Los aguascalentenses}

El caso de los aguascalentenses se trabajó desde dos subcasos: los colonos de la Colonia Vicente Guerrero (VG), que en sus propias palabras podrían definirse como los aguascalentenses "de la orilla" y los miembros del Club Deportivo y Social Campestre (CC), que se refieren a sí mismos como los aguascalentenses "de siempre". ¿Qué es lo que quieren decir con estas metáforas? Los aguascalentenses "de la orilla" expresaron su lugar en la sociedad aguascalentense en la periferia. No sólo su colonia está ubicada en el extremo sur-poniente de la ciudad, sino su situación económica, social y de poder se encuentra en los extremos de la centralidad. Por otra parte, los aguascalentenses "de siempre" hicieron claramente referencia a los aguascalentenses de origen que se reconocen como parte de las familias que forman la centralidad de la sociedad aguascalentense tradicional. A pesar de ser estas dos perspectivas extremas, ambas coincidieron en definir algunos rasgos de la identidad aguascalentense. ${ }^{12}$

Los nativos fueron muy claros al explicar que la sociedad aguascalentense se organiza en una red de relaciones familiares basada en el jefe de familia o patriarca. Las familias se identifican por el padre de familia y se tiene claro quiénes son sus descendientes. Tanto entre los aguascalentenses de la colonia VG como entre los socios del CC fue común la expresión "el hijo de", "R", el o la, de "A", aludiendo a que esa persona era "hijo o hija de". También en las historias personales y de la ciudad se hace continuamente referencia a linajes situados por el nombre del padre, del abuelo o el apellido. Se menciona que se traba-

12 Un explicación amplia de cómo los nativos definieron su identidad se encuentra en el libro Geografías ciudadanas y mediáticas (Padilla, 2012). 
jaba en la hacienda o el rancho de don "A", que se trabajaba con los " $\mathrm{L}$ ", o por ejemplo, en la tienda de los "B". Otras referencias comunes fueron a grupos políticos como los "O" o a grupos empresariales como los "B", "M" o los "R". Entre los aguascalentenses es reconocida esta red de familias, incluso los aguascalentenses de la colonia hicieron referencia a ellas, de manera más precisa por haber trabajado para ellas. Para los aguascalentenses del Club Campestre, se tiene mayor influencia en la ciudad al pertenecer a esta red de familias tradicionales por el hecho de tener capital económico, como es el caso de algunos originarios de la Ciudad de México. Lo expresaron de distintas maneras, pero evidentemente aluden a que el capital social se valora más como una pertenencia legítima y de influencia que sólo el capital económico.

El sistema de patriarcado se expresó claramente entre las dos perspectivas de nativos. Fue una constante la influencia de las decisiones del padre en el oficio o la profesión a seguir, dónde estudiar, trabajar y con quién casarse. Cuando narraron aspectos de su vida fue común que el padre fuera clave en sus decisiones y que se apoyara a los hijos e hijas al hablar de patriarca a patriarca, pidiéndole trabajo para ellos o algún otro favor.

\section{Las hidrocálidas}

Las mujeres que pertenecían al CC narraron cómo cuestionaron este sistema patriarcal. En este club social y deportivo, integrado por aguascalentenses nativos de arraigo y situación de privilegio, tradicionalmente la adquisición de la membresía era por herencia patrimonial, sólo los varones heredaban esta pertenencia. Los hombres, al cumplir la mayoría de edad, se volvían miembros autónomos y deberían pagar su propia acción. Por su parte, las mujeres permanecían socias bajo la tutela del padre mientras no se casaban, al hacerlo perdían su membresía si no la adquirían vía su esposo. Un grupo de socias encabezó una reforma por considerarla injusta para ambos sexos. Argumentaron que dados los cambios sociales, difícilmente un joven a los 21 años podría ser independiente económicamente y menos encabezar una nueva familia y membresía. Por otra parte, las mujeres reclamaron su derecho a heredar la acción de sus padres y extenderla a su esposo. ${ }^{13}$

13 Entrevistas realizadas a socias del club, de 50 y 49 años, el 23 de octubre de 2007 y el 14 de marzo de 2008. 
El club que antaño fue centro de encuentros de parejas y la continuidad de la elite local ha perdido este sentido entre las nuevas generaciones de mujeres que tienen otras expectativas más allá de contraer matrimonio.

Aventó el ramo y las niñas se hicieron para los lados, el ramo se cayó solito y nadie lo recogía, les decían: "A ti te llegó cerquita”, "Ay, no, tú, tú", no querían recoger el ramo y las que veíamos, decíamos: “Ay, no, no, no, no, qué barbaridad, sí que han cambiado las cosas". ¿Cómo ves a las niñas?, no quieren casarse. ${ }^{14}$

En contraste, el caso de las mujeres de la colonia popular Vicente Guerrero, relataron lo difícil que era su vida antes de la urbanización. En los terrenos, entonces llamados Las Huertas, no había pavimento, luz, drenaje, ni agua potable.

Y nos íbamos a lavar allá, a un terreno grandísimo de don Susano; tenía sembradíos y regaba, había mucha agua, nos íbamos para allá con toda la ropa, todas nos íbamos, en una carretilla acarreábamos la ropa, para lavar y luego de regreso para acá. ${ }^{15}$

Paulatinamente, el crecimiento de la ciudad llegó a Las Huertas, volviéndola parte de la zona conurbada. En su mayoría, las mujeres de la colonia empezaron a organizarse lideradas por doña Celia Durón a finales de 1990 para lograr que el asentamiento irregular y sin servicios se volviera una colonia con los servicios públicos necesarios.

A partir de este inicio un tanto informal de la organización, los miembros de la colonia lograron contar con electricidad y un templo, consiguieron alimentación y materiales para los niños en la escuela y realizaron la primera etapa de pavimentación, que se hizo ya a partir de un Comité de Concertación Social de la Presidencia Municipal (Bénard, 2007:371).

La trayectoria de doña Celia en la colonia ha merecido la atención de un estudio sobre organización ciudadana en la ciudad, el cual documenta cómo ella encabezó lo que en la colonia se le llamó "El Taller" que logró organizar a los colonos para gestionar con

14 Entrevista realizada a socia del club de 50 años, el 28 de marzo de 2008.

15 Entrevista realizada a Colona, 42 años, el 12 de octubre de 2007. 
las instancias gubernamentales y los partidos políticos de manera autónoma (Bénard, 2007). El 10 de noviembre de 1997 el ejido fue reconocido por las autoridades como la Colonia Vicente Guerrero, de tipo popular.

Durante la etnografía realizada en la colonia para este estudio, el caso de doña Celia y las historias sobre su figura persistieron aunque con una perspectiva distinta. Existe un consenso entre los colonos sobre la capacidad de liderazgo de Celia Durón y cómo en gran medida gracias a su trabajo se lograron beneficios para la colonia, la cual se tradujo en una sociedad civil llamada Redes de Desarrollo Comunitario, (REDEC), integrada por 30 diferentes colonias que tiene como propósito definir sus problemáticas, priorizarlas y gestar soluciones entre ciudadanos y las instancias gubernamentales. El trabajo de doña Celia se realizó durante los gobiernos del PRI y después llegó la alternancia con el PAN en el municipio y el Estado. En el periodo de estudio, quien era la jefa de colonia era una joven de veintitrés años. Su capacidad de liderazgo era sorprendente así como sus gestiones. Ella explicó claramente que estaba trabajando con el apoyo y filiación al PAN y que era necesario un cambio ante el liderazgo comunitario de más de 18 años de doña Celia. Hubo elecciones municipales en 2007 y las ganó el PRI. En las últimas conversaciones con la jefa de colonos, ella consideraba que quizás ahora resurgiera el liderazgo de Celia o de alguien de su equipo. Durante ese tiempo no fue posible conocer a doña Celia porque los colonos indicaron que se había involucrado en la venta fraudulenta de unos terrenos irregulares y estaba presa. El papel de las mujeres en la organización ciudadana de los colonos y desde la marginalidad, sin duda alguna es un aspecto que se identificó en este estudio que constituye una dinámica muy interesante.

Las mujeres jóvenes también se han incorporado al trabajo y algunas son obreras, laboran durante los turnos de noche para poder cuidar a sus hijos pequeños de día, y varias, al igual que la generación anterior de mujeres, son empleadas domésticas. Durante la estancia en la colonia fue muy común ver a las abuelas cuidar a sus nietos porque las mujeres trabajaban y aún no había guarderías públicas en el área. Las mujeres explicaron que era un nuevo problema que enfrentaba la familia, se requería el salario de las mujeres y con ello era común el que más de una familia nuclear vivieran juntas como una estrategia para enfrentar los gastos y apoyarse en la crianza de los niños. Sin embargo, se constató que la vida de las familias ampliadas

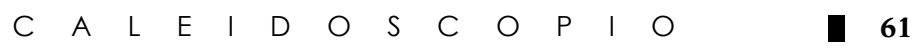


es difícil en términos de conflictos de poder y violencia intrafamiliar. ${ }^{16}$ Fueron las mujeres quienes con mayor agudeza cuestionaron los cambios que la modernización ha traído consigo a la vida familiar. Ven con preocupación que ahora es más difícil encontrar un empleo, hay más gastos que enfrentar en el nuevo estilo de vida urbano y la mayoría de los hombres no participan en las tareas del hogar y los hijos. Esta problemática abre varias preguntas sobre el papel de la modernización en los cambios en las condiciones de vida de la mujer. El cambio apunta a que la inequidad permanece entre los aguascalentenses, sin embargo su naturaleza se ha vuelto aún más compleja.

\section{Ciudadanas diversas y desiguales}

Los anteriores casos ilustran la creciente diversidad cultural y, por lo tanto, ciudadana, la cual es necesario visibilizar para tener una comprensión más nítida de la realidad ciudadana. Los discursos sobre ciudadanía tienden a homogeneizar y resaltar las semejanzas más que a construir propuestas más complejas que reconozcan la diversidad y tejan entre ella. Estos casos dan cuenta de las diferentes perspectivas de mujeres insertas en distintas identidades socioculturales, las cuales describen cómo se asumen como ciudadanas con relación a otras ciudadanas y ciudadanos en la ciudad.

En el caso de las japonesas, no son ciudadanas mexicanas en el sentido político, su estatus formal es de "no inmigrante visitante", ${ }^{17}$ sin embargo, son ciudadanas como habitantes de la ciudad y ejercen una ciudadanía cultural muy evidente. Su perspectiva como extranjeras es la de asumir una presencia discreta en la ciudad. Las mujeres japonesas tejen redes de manera muy estrecha entre ellas mismas, despliegan una gran capacidad de apoyo mutuo en un país ajeno, pero estas relaciones son muy escasas hacia otras mujeres que no formen parte de la comunidad japonesa con relación a la empresa transnacional. La lógica empresarial es la que se impone y el compromiso e identidad con la empresa define las demás, como la de género. Resalta la manera en la cual las japonesas han naturalizado el papel de la mujer en esta estructura, sin cuestionar o consi-

16 La observación en la colonia VG se realizó trabajando con las actividades regulares de un grupo de estudiantes de Trabajo Social de la Universidad, las cuales han identificado estas problemáticas

17 Reglamento de la Ley General de Población, fracción III. 
derar otras maneras de organización familiar ante las exigencias del ámbito laboral.

Debido a su condición de visitantes temporales, mientras sus esposos cumplen con un compromiso laboral por un tiempo, tanto en esta ciudad como en otras, no desarrollan un apego al territorio, sino con la empresa que trasciende su propio país. Algunas japonesas mostraron inquietudes de apoyar el desarrollo de sectores vulnerables de la población en esta ciudad, con una visión de voluntariado y orientadas como parte de los proyectos de responsabilidad social de la empresa; sin embargo, no ha habido proyectos por parte de sus empresas, el gobierno o de la ciudadanía que integren a esta comunidad de mujeres, con un gran potencial, a un trabajo a favor de la ciudad.

Las mujeres de la Ciudad de México, que han vuelto suya esta ciudad, tienen un relato interesante, dado que argumentaron que se han ganado un lugar como ciudadanas debido a sus aportes sociales y culturales y el haber vencido los prejuicios de los nativos hacia ellas. Subrayaron que llegaron a la ciudad con un estilo de vida familiar y personal más libre que se confrontó con el conservadurismo de Aguascalientes, y que de esto resultó un avance para la situación de la mujer. Además explicaron que han enriquecido la ciudad con una postura ciudadana más activa de exigencia de sus derechos y participación, a pesar de que consideran que injustamente esta actitud no ha sido comprendida y sí muy criticada por los aguascalentenses. Ellas la desplegaron en su momento cuando llegaron a la ciudad y debieron emprender varias iniciativas y acciones para lograr servicios públicos en sus colonias, espacios educativos para sus hijos y conformar su espacio laboral.

Consideraron, que aunque han pasado varias décadas de las primeras inmigraciones masivas de capitalinos a Aguascalientes, se distinguen los originarios de la gran ciudad por una perspectiva más crítica y activa como ciudadanos. Esta comunidad de mujeres, con base en su experiencia de vivir en una gran ciudad, que no resolvió muchos de sus actuales problemas a tiempo, expresó de manera muy clara sus preocupaciones en torno a Aguascalientes y la necesidad de una mayor organización ciudadana para enfrentarlas. No dieron cuenta de una organización formal entre ellas o de la comunidad de inmigrantes de la Ciudad de México, aunque sí de su participación individual en organizaciones de la sociedad civil.

Las mujeres aguascalentenses, en una situación de privilegio, se revisaron a partir de un club deportivo y social de tradición en la ciu-

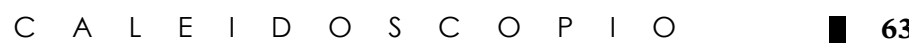


dad. La revisión de la historia de este club describe que la elite local ha sido muy activa y comprometida con el desarrollo de la ciudad, en gran medida porque ahí se han concentrado los políticos, empresarios, comerciantes y profesionales de la ciudad. Al revisar la perspectiva de las mujeres en esta comunidad, prevalece entre las generaciones mayores una integración y apoyo a los hombres desde la vida familiar y privada y las lógicas de participación como voluntarias, de acuerdo al puesto o trabajo de sus esposos, de ahí deriva su organización como ciudadanas y de trabajo a favor de su ciudad. Sin embargo, resaltan dos situaciones en esta comunidad, que desde la perspectiva de las mujeres cuestionan el orden que prevalece. Primero, el caso de las primeras generaciones que confrontaron la legitimidad de la herencia y pertenencia sólo a través de los varones, asumiendo que las hijas de los socios del club eventualmente seguirían siendo socias al casarse con un miembro de esta comunidad y no reconociendo su pertenencia por derecho propio. El segundo caso es el de algunas mujeres jóvenes, que anuncian cambios socioculturales al buscar otros propósitos en la vida que el sólo casarse con otro miembro de esta comunidad y vislumbrar la alternativa de formarse, tener una profesión y emigrar a otra ciudad o país.

Por último, el caso de las aguascalentenses que viven en una de las colonias marginadas de la ciudad, ellas fueron quienes desplegaron una mayor capacidad de organización ciudadana para mejorar la infraestructura de su colonia. Este trabajo ciudadano tiene vetas independientes, pero además historias y relaciones con los partidos políticos y gobiernos en turno que busca el favor del voto de esta población. Resalta el papel activo de las mujeres en esta colonia, sus cuestionamientos a los prejuicios que viven debido a su contexto de pobreza que deriva en que son señalados como delincuentes y sus duras condiciones de vida que no han cambiado con los procesos de modernización de la ciudad. Es muy interesante cómo el paso de una vida rural a la industrialización no ha mejorado las condiciones de vida de la mujer y, por el contrario, su incorporación al ámbito laboral le ha presentado desafíos más complejos.

Estos casos muestran la diversidad de situaciones e identidades culturales desde las cuales las mujeres asumen su papel como ciudadanas en la metrópoli. Las redes, organización y prácticas ciudadanas de estas mujeres, y en general de las comunidades en las cuales se insertan, surgen en primera instancia del sentido de pertenencia y 
lógicas de éstas y no a partir de una comunidad política mayor como el municipio, el estado o el país. Las mujeres de estas comunidades muestran, a pesar de habitar en la misma ciudad, las diferencias y principalmente las desigualdades que se viven lo cual permite una aproximación a comprender por qué resulta difícil la construcción de organizaciones entre mujeres a través de estas diferencias culturales.

Las japonesas no participan ni se comprometen con la vida ciudadana, a pesar del gran aporte que podrían constituir para esta ciudad, esto debido a su desapego como extranjeras, prejuicios, temor por el ambiente de inseguridad y la falta de una organización previa entre instituciones y empresa. Las mujeres de la Ciudad de México argumentan que sí ha habido un esfuerzo ciudadano de su parte, pero han sufrido prejuicios y poca aceptación por parte de las mujeres aguascalentenses que se encuentran insertas en sus propias redes sociales, con poca aceptación de quienes no pertenecen a ellas. Entre las aguascalentenses, se dio cuenta de una participación ciudadana por parte de las mujeres ligadas a las lógicas ciudadanas de los hombres de la elite local con un papel de apoyo secundario, pero se manifestaron además signos de cuestionamiento y cambio. Finalmente, las mujeres aguascalentenses de una colonia marginada mostraron sus esfuerzos por organizarse y lograr mejoras para su comunidad, a pesar de las estructuras de poder y políticas.

El afinar la mirada hacia las mujeres en estas identidades describe cómo se encuentran insertas en una doble lógica de subordinación, la de género; y aquellas que también viven los hombres a partir de la empresa, la otredad y la pobreza. Sin embargo, a pesar de que existe una convergencia en los problemas que enfrentan, no existe una organización de mujeres o ciudadana a través de la diferencia, sino una población cada vez más heterogénea y desigual que se integra para resolver su vida cotidiana al interior de sus identidades próximas de pertenencia, y no a partir de sus comunidades políticas.

Este trabajo se limita a dar cuenta de unos cuantos casos y falta mayor profundidad en el análisis de cada uno, debido a que se desprende de un estudio mayor que no partió del propósito de estudiar el caso de las mujeres en específico; sin embargo, abre una nueva agenda en la necesidad de estudiar a las mujeres y su ciudadanía a partir del perfil sociocultural que adquieren en distintos escenarios. Este aporte permite aproximarnos a entender por qué se dificulta una articulación o perspectiva en común entre mujeres y ciudadanas,

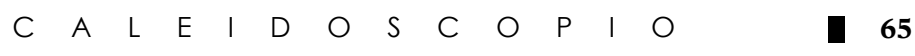


y por supuesto, entre la comunidad más amplia de ciudadanos para organizarse y mejorar el entorno en el cual viven. Es difícil el desafío de los ciudadanos y los gobiernos de generar procesos que sumen propósitos comunes entre las diferencias y desigualdades que se viven en la realidad de una comunidad, como la ciudad o el Estado-Nación; sin embargo, lo primero es reconocer que éstas impiden que se integre la población para enfrentar sus problemas como una comunidad política.

\section{REFERENCIAS}

Bénard, S. (2007). Dos mujeres, dos trayectorias de organización comunitaria. En Padilla, Y. (Coord.). Línea Curva. Historias de mujeres en Aguascalientes (369-388). México: Instituto Aguascalentense de las Mujeres.

Holstein, J. y Gubrium, J. (1998). Phenomenology, Ethnomethodology, and Interpretative Practice en Strategies of Qualitative Inquiry. En Denzin y Lincoln (Eds.). Strategies of Qualitative Inquiry (137-157). Thousand Oaks: SAGE.

Jäger, S. (2003). Discurso y conocimiento: aspectos teóricos y metodológicos de la crítica del discurso y del análisis de dispositivos. En Wodak y Meyer (Coords.). Métodos de análisis crítico del discurso (61100). Barcelona: Gedisa.

Knight, K. y Harnish, J. (2006). Contemporary Discourses of Citizenship. Review of Educational Research, 76(4), 653-690.

Kymlica, W. (1996). Ciudadanía multicultural. Una teoría liberal de los derechos de las minorías. Barcelona: Paidós.

Madoo, P. y Niebrugge-Brantley, J. (1993). Teoría feminista contemporánea. En Ritzer, G. Teoría Sociológica Contemporánea (353-409). México: McGraw-Hill/Interamericana de España.

Marshall, T. H. (2005). Ciudadanía y clase social. En Marshall, T.H. y T. Bottomore (Coords.). Ciudadanía y clase social (11-36). Buenos Aires: Editorial Losada.

Moreno, A. (2005). Una reconstrucción feminista de la ciudadanía. En Carrió, E. y D. Mafia (Comps.). Búsquedas de sentido para una nueva política (189-218). Barcelona: Paidós.

Ortiz, R. (2003). Lo próximo y lo distante. Japón y la modernidad-mundo. Buenos Aires: Interzona. 
Padilla, R. (2012). Geografías ciudadanas y mediáticas. México: UAA.

Fairclough, N. (2003). Analysing discourse. Textual analysis for social research. London: Routledge.

Ramírez Sáiz, J.M. (2003). De las ciudades-Estado y la ciudadanía local a las ciudades globales y la ciudadanía mundial. México: Universidad de la Ciudad de México.

Rosaldo, R. (1999). Ciudadanía cultural, desigualdad, multiculturalidad. En El Bordo, retos de frontera. No. 3. Recuperado el 8 de mayo de 2008 en: http://www.tij.uia.mx/elbordo/vol03/bordo3_ciudadanial.html.

Sermeño, Á. (2004). Ciudadanía y teoría democrática. Revista Metapolítica, 8(33), X-X.

Organización de las Naciones Unidas para la Educación, la Ciencia y la Cultura (UNESCO). (2001). UNESCO Universal Declaration on Cultural Diversity. Recuperado el 22 de febrero de 2016 en: http:// portal.unesco.org/en/ev.php-URL_ID=13179EURL_DO=DO_TOPICEURL_SECTION=201.html.

Van Zoonen, L. (1994). Feminist media studies. London: SAGE 